\title{
Two New Books about European Amphibians and Reptiles
}

Reptiles and Amphibians. Naturalists' Handbook 31. Ecology and Identification. 2013. Trevor J.C. Beebee. Pelagic Publishing, Exeter, UK. v + 170 pp. Paperback - ISBN-13: 978-1-907807-45-9 (also available as an ePub, pdf, and for the Mobi reader). $£ 19.99$ (approx. \$31) (not available at this time through any US outlets).

\section{Amphibian Biology. Volume 11. Status of the Conservation and} Decline of Amphibians: Eastern Hemisphere. Part 3. Western Europe. 2013. Harold Heatwole and John W. Wilkinson (eds.). Pelagic Publishing, Exeter, UK. 108 pp. Paperback ISBN-13: 978-1-907807-52-7 (also available as an ePub, pdf, and for the Mobi reader). £59.99 (approx. \$93).

Trecently reviewed an application for promotion by a colleague who had spent much of his career in Europe. I was surprised and a bit dismayed when faced with the fact that I had been totally unaware of his body of work on European amphibians and reptiles. I believe this speaks to a greater reality, a bias if you will of American herpetologists who focus their attention solely on the Western Hemisphere - or, if they venture into the Old World, they restrict their efforts largely to the tropics. Guilty of the former and innocent of the latter only because the opportunity to work in tropical regions of the Eastern Hemisphere has not arisen, I am the first to plead ignorance of the rich European herpetological tradition. So, when the opportunity arose to review two new books about the herpetofauna of the United Kingdom (UK) and the conservation status of amphibians in western Europe, I jumped at the opportunity.

The two books are quite different, and I justify combining them in this review only because of the common geographic focus. Beebee's guide is part of a series of "Naturalists' Handbooks" directed toward the nature lover. In sharp contrast, the volume edited by Heatwole and Wilkinson, although also one in a series, is a compilation of technical reports aimed at professional herpetologists and conservation biologists. Those differences are reflected clearly in tone and production values.

Beebee's guide is profusely illustrated and, in addition to keys and illustrations of 20 native and established introduced species in the UK, includes extensive sections detailing basic biology, taxonomy and evolutionary relationships, ecology and conservation, and instructions for studying amphibians and reptiles. Aspects of the life histories of various species are incorporated throughout those sections instead of the more traditional stand-alone accounts for the various species. I was especially intrigued by a chapter on "How schools can help," which encourages participation in collaborative efforts by groups such as school classes "to make a particularly valuable contribution to a body of information that underpins conservation management of amphibians and reptiles." Beebee describes data collection and potential projects in field and lab, emphasizing the value of students having "the chance

\section{Amphibians and reptiles}

TREVOR BEEBEE

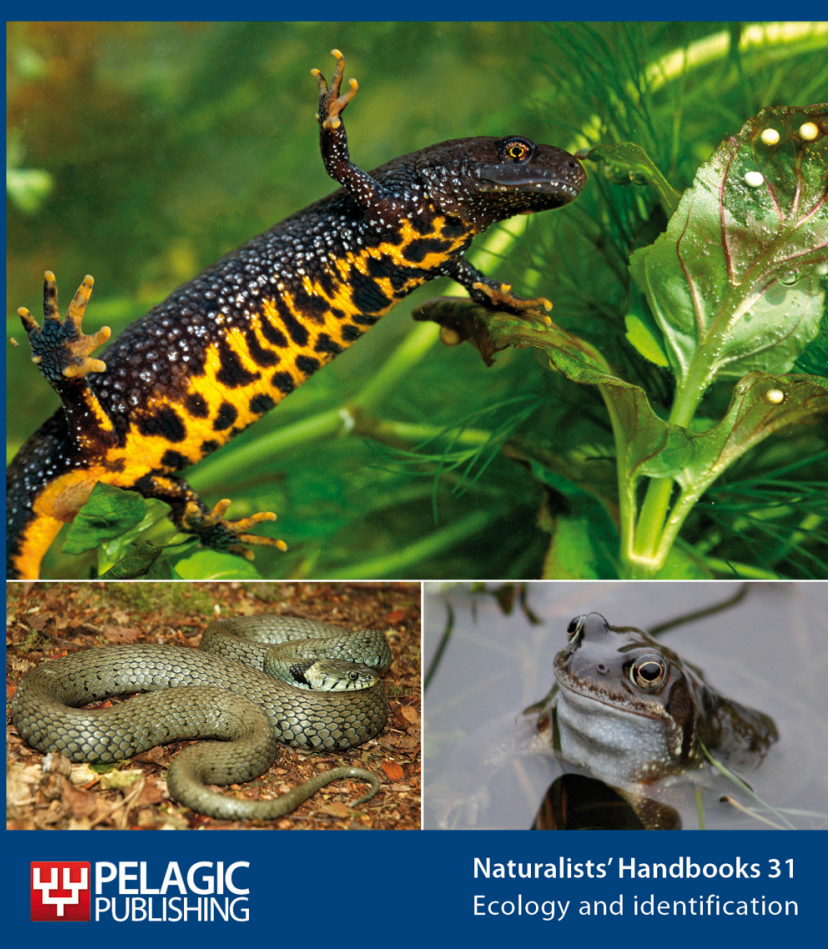




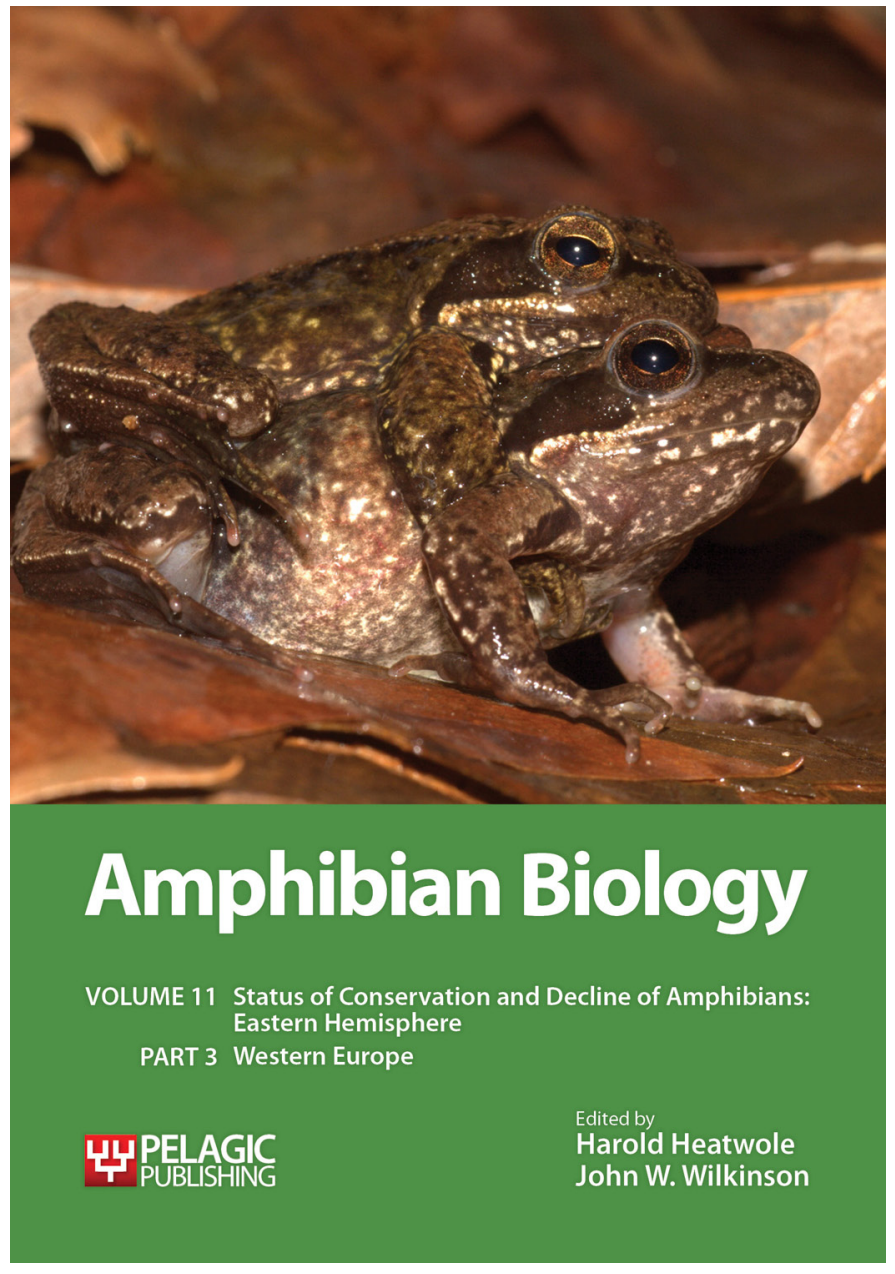

to see wild animals and experience the excitement of completely new discoveries based on the simplest of scientific methods." A later chapter, titled "Working with amphibians and reptiles: some basic essentials," addresses "legal niceties," details handling methods and identification issues, and presents information about investigative methods that includes hypothesis testing and even statistical methods (!). The chapter also lists outlets for publication and herpetologically oriented meetings in which a reader could participate. I must say I was impressed by the assumption of sophistication Beebee expressed for his audience. The book concludes with "useful addresses and links," a list of references, and an index.

Although he provides a list of species that have been found occasionally or have established breeding populations for short periods (including five American taxa), Beebee chooses not to address them further, instead directing the reader to a recent guide by Inns (2009. Britain's Reptiles and Amphibians. Wild Guides, Old Basing, Hampshire). Seven keys (1. adult and immature newts; 2 . newt eggs, larvae, and metamorphs; 3. frogs and toads (adults and metamorphs); 4 . frog and toad spawn; 5. frog and toad larvae; 6. adult and hatchling limbed lizards; 7 . adult snakes) are straight-forward and user-friendly (even someone who has never encoun- tered a dichotomous key will find them easy to navigate) and include directions to illustrations and distribution maps for each taxon. A section of color plates, several black-andwhite photographs that exploit the wide margin obviously designed for just that purpose, and a line drawing provide ample opportunity to confirm the identities of an animal in hand. Interspersed among the keys are sections with general information on the species addressed in each key along with instructions on sexing animals. Maps are confined to a separate section and each includes color-coded indicators of areas where a species is "sparsely present," where it is "relatively common and widespread," or where populations have been reintroduced, the latter indicative of efforts to conserve native species that have fallen on hard times. Because all of Ireland is included, although only Northern Ireland is part of the UK, I quickly checked the maps to see if, according to legend, Saint Patrick had succeeded in driving the snakes out of Ireland. Apparently he did. None of the four snakes known from the UK occur in Ireland — and, maybe just to play it safe, neither does the Slow-Worm (Anguis fragilis). Whether this suggests that Saint Patrick was unable to distinguish snakes from legless lizards or whether Slow-Worms never occurred in Ireland is uncertain.

I like Beebee's book and am especially appreciative of his efforts to engage readers in studies of or conservation efforts aimed at amphibians and reptiles. I enjoyed the many marginal comments and illustrations, but wanted more of them - many pages have only an empty space along a rather narrow text column. In addition, I became a bit frustrated when trying to learn more about a particular species. Instead of consulting an account devoted to that species, I had to search through the book for information on life history, elsewhere for illustrations, and still somewhere else for a distribution map. Also, I wish he (and other European authors) would adopt the convention of capitalizing formal common names, if only to set them apart. Lastly, because I am not familiar with the common names of the species included in the guide, I wish he had listed scientific names more frequently, as that would have helped me keep track of which species was being discussed (this was particularly noticeable in the otherwise very informative table listing terrestrial and, when applicable, aquatic habitats for each species).

The volume edited by Heatwole and Wilkinson consists of eight independently authored chapters numbered 31 to 38 , reflecting their place in this series. The first and only extensive contribution deals with infectious diseases that threaten Europe's amphibians. The other chapters address conservation concerns and population declines in various nations (Ireland, Britain, The Netherlands, Belgium, France, Spain, and Portugal). Despite admirable editorial efforts, the book suffers from an almost inevitable unevenness that reflects the many authors, varying degrees of detail, different styles, and 
the unavoidable redundancies emanating from the reality that multiple nations often share the same species and many of the same problems affect the amphibians in different nations (after all, amphibians do not recognize political boundaries). The redundancies in the chapters devoted to individual nations also precluded any in-depth coverage of issues or case studies demonstrating what has and has not been successful. In fact, those same redundancies raise the question why these chapters were not synthesized into a synopsis of what is happening in the region (and I suspect what is happening elsewhere in much of Europe), allowing for considerably more detailed coverage of issues (as is the case for the infectious diseases chapter). What they all share beyond a certain superficiality (only two of the chapters devoted to individual nations exceed 10 pages in length) is a dry tone and the extensive use of jargon that would exclude most nature lovers, regardless of their commitment to conservation, and a lack of illustrations, which is acceptable in a technical work directed to a sophisticated professional audience - although even the most jaded academics enjoy pretty or informative photographs.

I found the book to be useful, especially since it emphasized the unfortunate reality that many European amphibians suffer from the very same threats as those elsewhere in the world. I also came away with the impression that we could learn much from European herpetologists and conservation biologists, if only because Europe has been densely populated and developed far longer than the Americas. Consequently, the lessons learned there should readily translate to applications elsewhere in the developed (and developing) world. That said, despite some degree of utility, I wanted so much more. I question the decision to publish these accounts in such small, very highly priced increments (this is "part 3" in "volume 11") instead of in fewer volumes (what bone-headed decision led to the "parts" being published separately?). If consolidated, similar themes could be synthesized, case studies included, and successful solutions explored more thoroughly.

Production quality is high for both books, especially for paperbacks, but the list prices are substantial. This frequently is the case for European books sold in the US, although the price of the Heatwole/Wilkinson volume, which approaches a dollar per page, is exorbitant by any standard, even for a narrowly focused work printed in limited numbers. As these volumes become available on this side of the Atlantic, I hope steep discounts from volume sellers will render them a bit more affordable. If you cannot wait that long, the publisher does provide a $20 \%$ discount on any purchase of two books from their website (www.pelagicpublishing.com).

In summary, I strongly recommend the Beebee book, despite the few quibbles mentioned above. It provides a view of a herpetofauna that is poorly known and underappreciated on this side of the Atlantic. In addition, it is an admirable model of efforts to engage the public in herpetology and conservation biology - a most worthy goal. It would be a worthwhile addition to the library of any nature lover. I am considerably less enamored with the Heatwole/Wilkinson volume. Despite some obvious utility, the high cost, the limited coverage, the lack of synthesis, and the overt redundancies lead me to recommend that you wait until someone eventually publishes the synoptic overview that is so obviously missing in the few pieces included in this book. In the meantime, readers interested in amphibian conservation should invest in the excellent treatise edited by S.N. Stuart et al. (2008. Threatened Amphibians of the World), which I reviewed in 2008 (Iguana 15:243-244).

Robert Powell

Avila University

Kansas City, Missouri 